\title{
DA CONCEÇÃO ATÉ À GESTÃO, MANUTENÇÃO E OPERAÇÃO. SISTEMA ABASTECIMENTO DE ÁGUA A PORTEL
}

\author{
Susana Freitas ${ }^{(1)}$, Luís Ribeirinho ${ }^{(1)}$, Ana Amélia Santos ${ }^{(2)}$ \\ (1) TPF - CONSULTORES DE ENGENHARIA E ARQUITETURA, S.A., Lisboa \\ (2) EPAL - EMPRESA PORTUGUESA DAS ÁGUAS LIVRES, S.A., Lisboa
}

\begin{abstract}
Resumo
O projeto de execução do Sistema de Abastecimento de Água a Portel foi desenvolvido pela TPF Consultores para a EPAL/AdVT, com base na metodologia Building Information Modeling (BIM). O projeto inclui a conceção de infraestruturas de abastecimento como reservatórios, adutoras e estações elevatórias. No seio da EPAL/AdVT, o Projeto do Sistema de Portel teve como propósito dar início a um ciclo de execução de projetos nesta metodologia, e, como objetivo futuro, melhorar e otimizar a gestão de ativos e a operação e manutenção. Para isso, promoveu-se a interligação de todas as áreas de gestão técnica da EPAL/AdVT logo na fase inicial do processo de decisão e implementação. A aplicação desta metodologia permitiu ainda uma gestão integrada da informação das várias componentes do projeto, tornando possível um fluxo estruturado de partilha de informação entre os diferentes intervenientes. Por outro lado, o envolvimento de todas as áreas técnicas da empresa, que irão receber o Ativo na forma de um modelo BIM, permitiu incorporar as respetivas necessidades futuras de cada área técnica, trazendo naturalmente mais-valias na futura gestão do Ativo.
\end{abstract}

\section{Introdução}

O projeto de execução do Sistema de Abastecimento de Água (AA) a Portel foi desenvolvido com a Metodologia BIM. A utilização desta Metodologia na elaboração deste Projeto teve, numa fase inicial, como objetivo, usufruir apenas das mais-valias inerentes à sua aplicabilidade na fase de elaboração de um Projeto de Execução.

Contudo, no desenvolvimento do Projeto e num trabalho conjunto com a EPAL/AdVT, definiuse uma estratégia mais alargada, a qual visou a preparação dos modelos criados no âmbito do Projeto de Execução, para a sua utilização subsequente pelo Empreiteiro, na fase de execução da obra, e pela EPAL/AdVT, durante todo o ciclo de vida da infraestrutura.

Na elaboração do Projeto não houve lugar à elaboração de um BEP formal, tendo-se definido os requisitos a implementar nos Modelos, bem como o respetivo sistema de classificação durante as reuniões realizadas, em estreito diálogo com a EPAL/AdVT. 


\section{Descrição do Sistema de Abastecimento de Água (AA) a Portel}

O Sistema de Abastecimento de Água (AA) a Portel tem como objetivo alimentar todo o concelho de Portel, através do abastecimento de sete pontos de entrega, a saber: Oriola, São Bartolomeu do Outeiro, Portel, Monte do Trigo, Amieira, Alqueva, Santana e Vera Cruz.

As intervenções previstas realizar no âmbito do Projeto de Execução realizado tiveram como objetivo:

- A redução dos consumos de energia e aumento da fiabilidade do sistema;

- O aumento da contribuição das captações subterrâneas;

- O aumento do volume de reserva do sistema.

Com base nos objetivos definidos, o Projeto de Execução incluiu as seguintes intervenções:

- Remodelação da EE da ETA do Alvito

- Construção do Reservatório de Regularização do Sistema

- Construção da Adução para São Bartolomeu do Outeiro

- Remodelação da Câmara de Manobras do Reservatório do Reguenguinho

- Intervenções nos Furos das Taipinhas

- Construção da Adução Taipinhas - Portel

- Ampliação do Reservatório de Portel

- Ampliação do Reservatório de Monte do Trigo

- Remodelação dos Circuitos das Captações de Santana

- Construção da EE das Taipas e Adução para Vera Cruz.

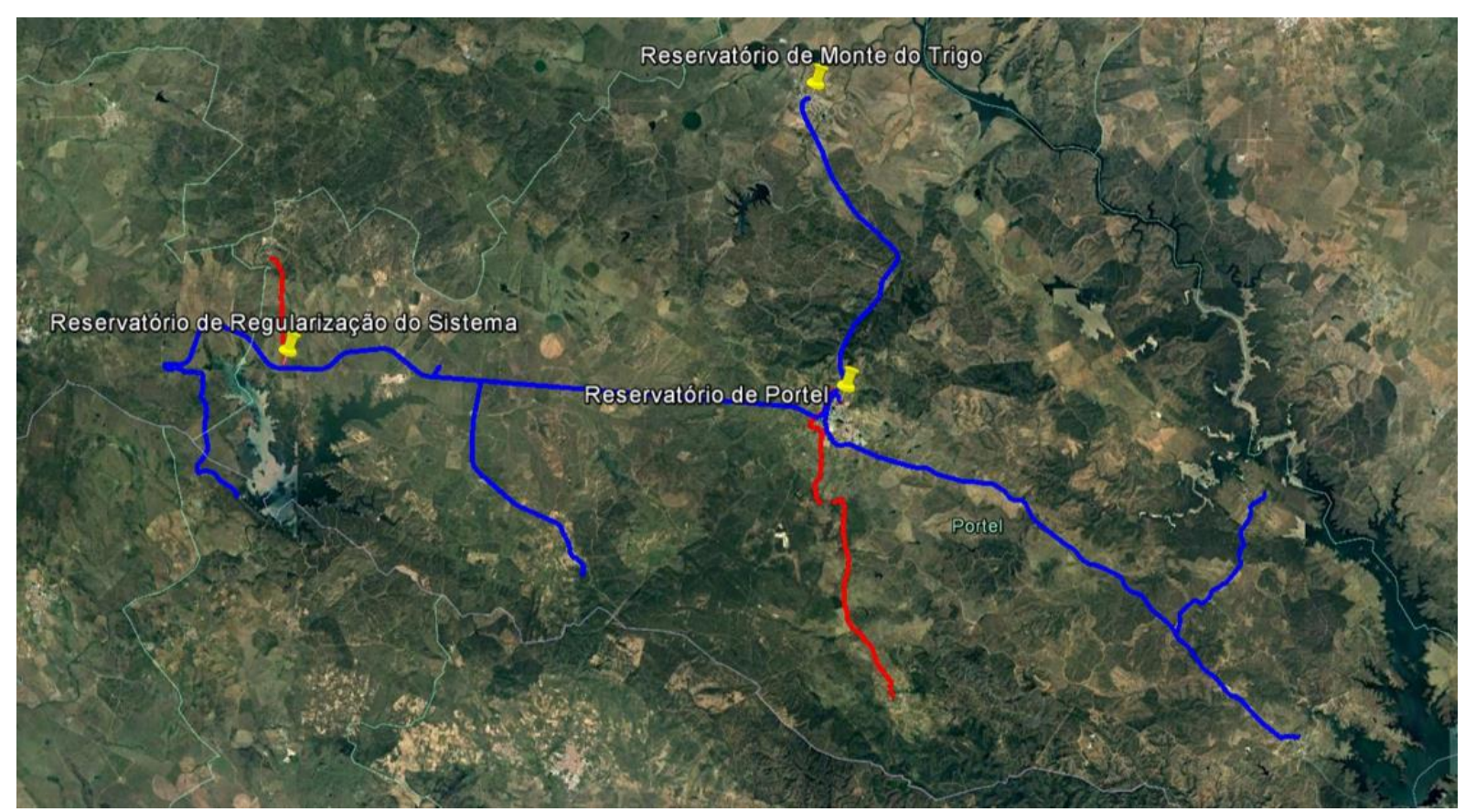

Figura 1: Sistema de Abastecimento de Água (AA) a Portel. 


\section{A Metodologia BIM na fase de Projeto de Execução}

A aplicação da metodologia BIM ao processo AA Portel permitiu uma gestão integrada da informação das várias componentes do projeto, tornando possível um fluxo estruturado de partilha de informação entre os diferentes intervenientes.

\subsection{O Modelo}

O projeto do Sistema de Abastecimento de Água (AA) a Portel deu origem à elaboração de 18 modelos independentes, desenvolvidos em Autodesk Revit, elaborando-se um Modelo, para cada uma das infraestruturas projetadas. Para a definição deste tipo de metodologia contribuíram vários fatores:

- O limite do plano de trabalho $(32 \mathrm{~km})$;

- A diversidade destinta de informação relevante a definir por tipo de infraestrutura, nomeadamente os níveis, as vistas, os layouts, as tabelas de equipamento;

- A dimensão dos ficheiros criados.

Não obstante a opção por criar modelos independentes por infraestrutura, reuniu-se em três modelos gerais a definição das intervenções, do Sistema de Abastecimento de Água (AA) a Portel, que tiveram por base três áreas geograficamente distintas. Os modelos gerais incluíram os modelos de cada infraestrutura, a superfície topográfica e o traçado das condutas adutoras, importados do Civil 3D.

\subsection{Interação com o Dono de Obra}

Desde o início do projeto, os Modelos fizeram parte do material apresentado em reunião de revisão do projeto, com o Dono de Obra (DO).

Tendo em conta a complexidade de um Sistema de AA, a visualização 3D das infraestruturas revelou-se muito importante para a explicação da solução proposta, que muitas vezes não são tão facilmente apreendidas, pelos vários interlocutores, através da apresentação das tradicionais peças desenhadas.

Durante a elaboração do Projeto a informação foi partilhada com o DO através da plataforma BIM360, onde foram disponibilizadas as várias versões dos Modelos elaborados. Na plataforma a informação foi disponibilizada e organizada por especialidade, com o objetivo de permitir a análise e os comentários dos diversos intervenientes da EPAL/AdVT.

\subsection{Dimensionamento e Definição das Formas}

Os Modelos elaborados, para as várias infraestruturas projetadas no âmbito do Sistema de Abastecimento de Água (AA) a Portel, incluíram as especialidades de hidráulica, estruturas e eletricidade, entre outras.

A conceção preliminar da definição de formas das infraestruturas, permitiu à especialidade de estruturas exportar os elementos necessários ao dimensionamento das mesmas, e completar, atualizando sempre que necessário as espessuras e as armaduras, no modelo inicialmente concebido na especialidade de hidráulica.

Em paralelo, a especialidade de eletricidade implantou todos os equipamentos elétricos, nomeadamente luminárias, detetores de presença, botoneiras, tomadas, no modelo, garantindose uma total compatibilidade entre todos os equipamentos. 
Todas as especialidades intervenientes no projeto partilharam e colaboraram de forma direta no mesmo modelo, sem qualquer esforço, utilizando os Worksets do Autodesk Revit para a separação dos elementos por especialidade.

\subsection{Equipamentos e Atravancamentos}

A conceção de cada uma das infraestruturas teve em conta a definição dos equipamentos que delas farão parte, respeitando-se os atravancamentos dos mesmos, em função das suas características.

A modelação recorrendo à utilização de objetos parametrizados permite no decorrer do processo atualizar os equipamentos, consequência da necessidade de alterar as suas características, garantindo-se que os atravancamentos são respeitados, ficando validada a exequibilidade em fase de obra.

\subsection{Identificação de Interferências}

A criação de um modelo único partilhado entre as especialidades intervenientes no projeto, para cada infraestrutura, facilitou a identificação de possíveis colisões, garantindo-se que, na solução final proposta, as mesmas são inexistentes.

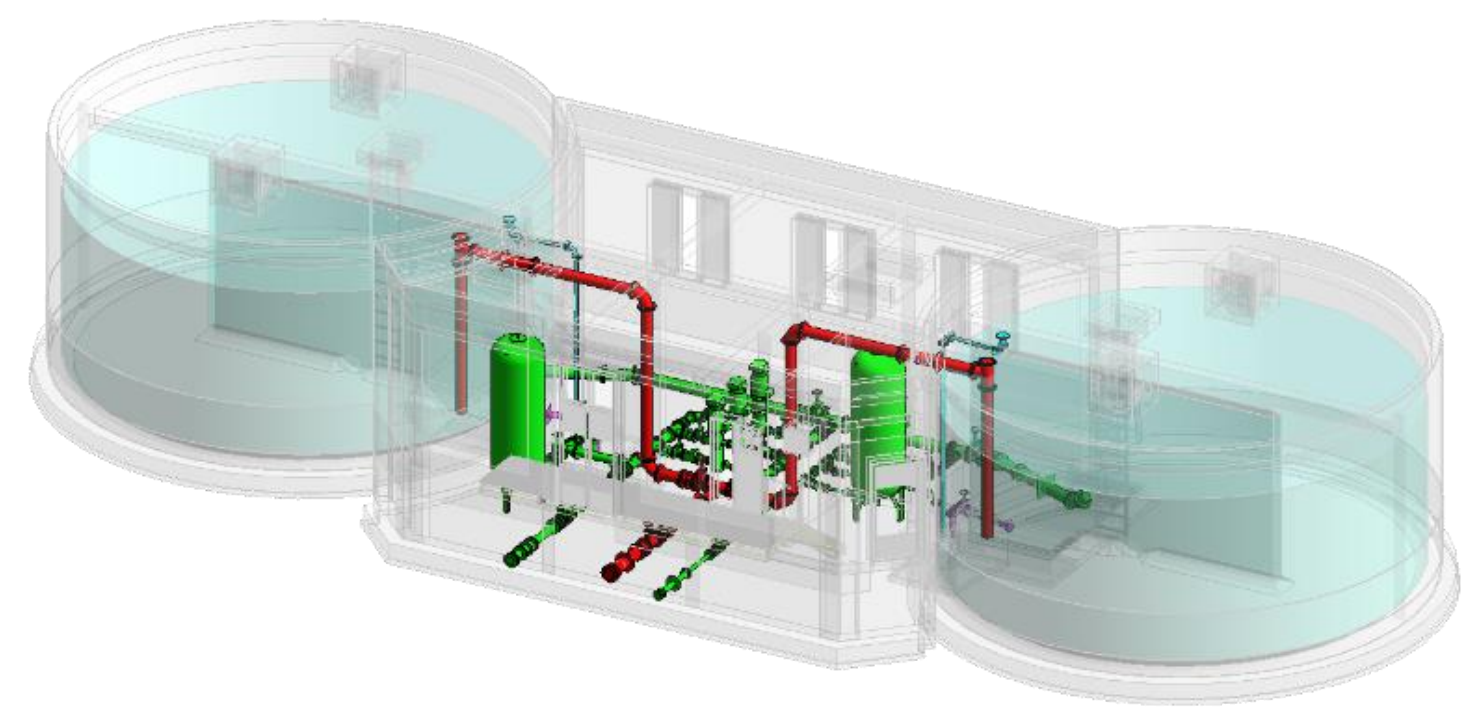

Figura 2: Interferências entre circuitos hidráulicos.

\subsection{Quantificação dos Trabalhos e Estimativa Orçamental}

Cada um dos modelos concebidos foi elaborado com famílias/elementos devidamente caracterizados e catalogados, que permitiu a criação de tabelas quantitativas, organizadas por tipo de trabalho, exportadas para Excel, de forma a serem utilizadas na elaboração das medições. 


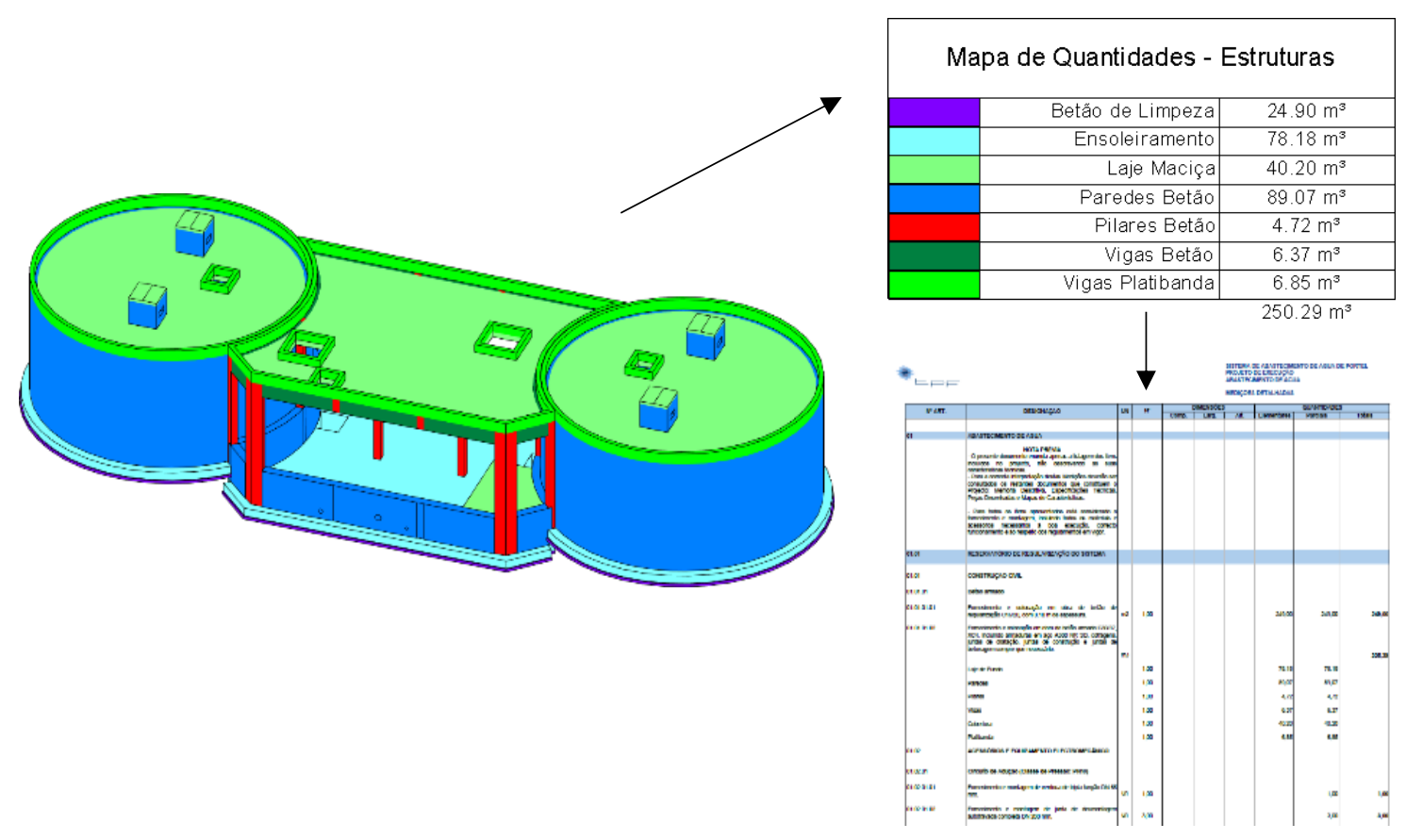

Figura 3: Extração do mapa de quantidades.

\section{A preparação do Modelo BIM para a gestão de ativos e a operação e manutenção}

Para além da visualização do modelo, durante as reuniões com o DO, foram surgindo várias questões relacionadas com a futura utilização do modelo, nomeadamente no que diz respeito à gestão de ativos e à operação e manutenção. Sendo o DO responsável por todos os custos do ciclo de vida das infraestruturas que gere, está consciente do peso que a operação e manutenção tem no valor total, reconhecendo, por isso, a importância de investir na otimização desta fase. A principal ideia transmitida foi a de que o modelo deveria acompanhar todo o ciclo de vida da infraestrutura. Esta simples frase transporta alterações profundas na forma como a informação deve circular. O modelo passa a ser um transportador de informação (Figura 4). Uma das principais funções da área de cadastro consiste em passar a informação do projeto para os sistemas de gestão da EPAL/AdVT, nomeadamente a das fichas técnicas produzidas pelo empreiteiro. O modelo BIM permite que esta função seja automatizada. Esta automatização irá traduzir-se na redução de recursos e de tempo necessários ao cadastro, bem como na redução do risco de erro humano inerente à digitação da informação. 


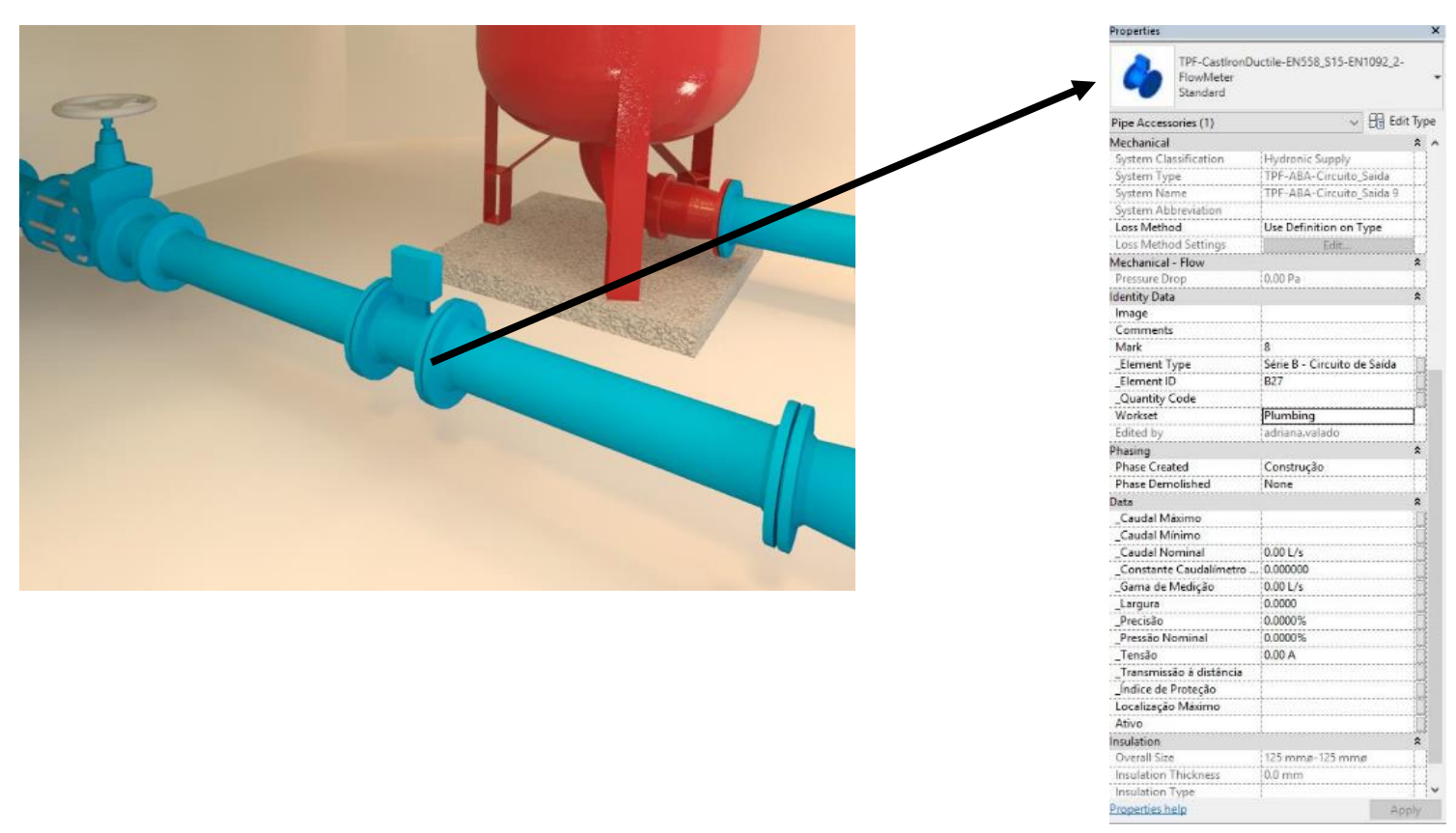

Figura 4: Identificação e caracterização dos ativos.

Preparar o modelo para este efeito, implicou um trabalho conjunto da TPF Consultores e de todas as áreas técnicas da EPAL/AdVT que irão receber o Ativo na forma de um modelo BIM. Reunir estas entidades na fase de conceção permitiu incorporar as respetivas necessidades futuras de cada área técnica. Tornou-se também uma oportunidade para uniformizar internamente alguns processos. O resultado prático desse esforço redundou numa lista de características por elemento que devem existir no modelo, uma vez que serão necessárias à gestão de ativos, à operação e manutenção. Ao introduzir essas características na fase de projeto de forma sistematizada, estamos a definir claramente os requisitos de informação para o empreiteiro, evitando que falte informação por desconhecimento, ou que se produza informação desnecessária. Para além disso, viabilizamos a recolha automática dessa informação. Note-se que a relação entre o modelo e a base de dados (BD) do DO é feita através do sistema de codificação de ativos da EPAL/AdVT. Os códigos são introduzidos nos parâmetros dos elementos do modelo, permitindo o mapeamento entre o modelo e a BD.

Durante o processo promoveu-se o diálogo com o departamento de informática da EPAL/AdVT onde se abordou a questão da integração da informação. Durante a fase de elaboração do projeto não foi possível testar de forma efetiva esta integração, mas foi reconhecido que a utilização do sistema de classificação interno da EPAL/AdVT e as designações das características dos equipamentos da sua BD, nos Modelos, garantiria a integração pretendida.

Do lado do projetista, desenvolveu-se um add-in para o carregamento automático dos parâmetros nos elementos (família) (Figura 6). Para executar o add-in foi necessário preparar um documento .txt com as famílias exportadas do modelo Autodesk Revit e dois documentos Excel com os parâmetros a criar. Para criar qualquer parâmetro partilhado numa família Autodesk Revit, foi necessário criar primeiro esse parâmetro no documento de texto dos parâmetros partilhados desse projeto. Por essa razão, existem dois documentos Excel. Um deles associa os parâmetros aos tipos, o outro estabelece a relação entre as famílias Autodesk Revit exportadas do modelo e a lista de características fornecida pelo DO. 


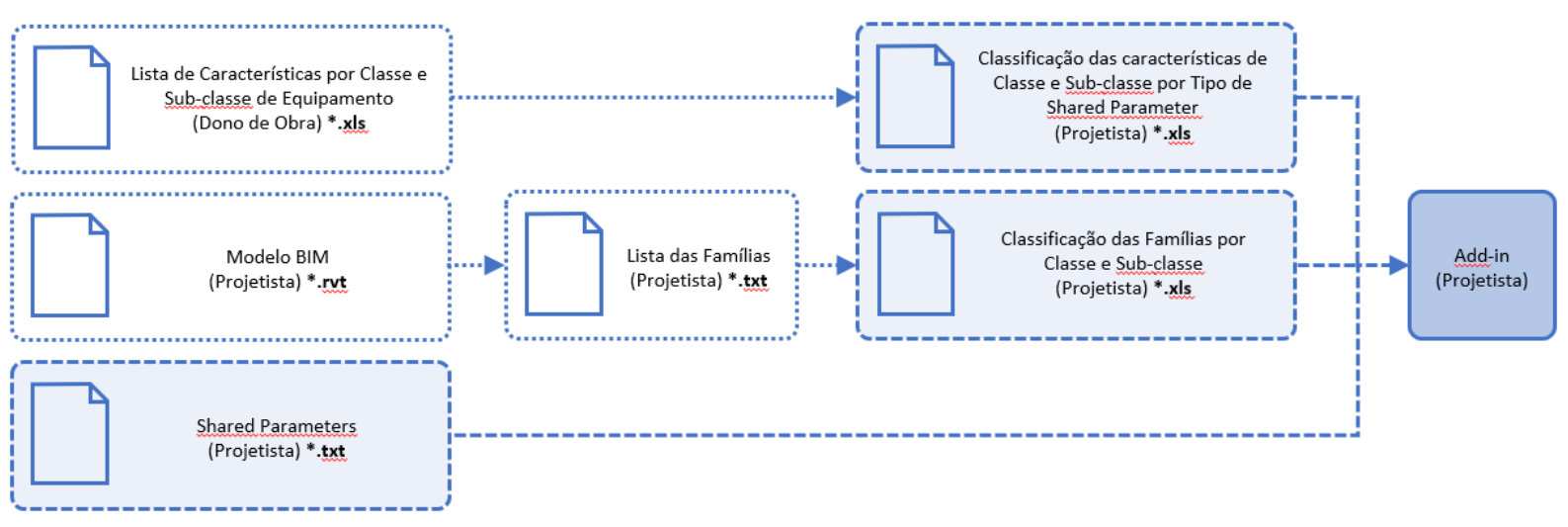

Figura 5: Diagrama do fluxo de informação para introdução no add-in de criação automática de parâmetros no Autodesk Revit.

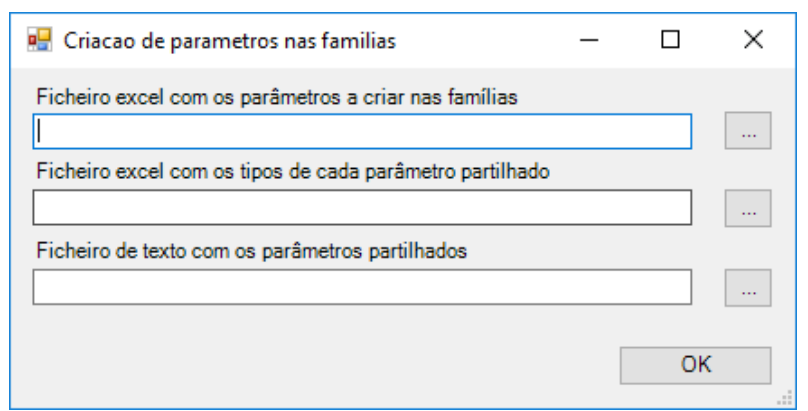

Figura 6: Add-in para criação automática de parâmetros no Autodesk Revit.

A ligação entre o modelo e a BD dos sistemas de gestão do DO deve ser bidirecional, ou seja, deve permitir alimentar a BD no final da empreitada, mas deve também permitir manter o modelo atualizado, sempre que se substitua um equipamento no decorrer da normal operação da infraestrutura.

\section{Conclusões}

O desenvolvimento do projeto AA Portel, com a metodologia BIM contribuiu para a execução de um projeto pioneiro dentro da EPAL/AdVT, e da TPF, criando uma nova abordagem no modo de elaboração de projetos (com a intervenção, desde o início do processo, com outras áreas técnicas que tradicionalmente só interviriam no final da obra, nomeadamente gestão de ativos, operação e manutenção. Esta forma de abordagem, desencadeia dentro das empresas, o desenvolvimento das tendências globais de modernização ao nível da execução dos projetos e conduz à possibilidade de se desenvolver projetos mais complexos, com mais qualidade, e que permitam uma construção mais económica, em prazos mais reduzidos, e com menos riscos associados.

Por outro lado, o envolvimento de todas as áreas técnicas da EPAL/AdVT, que irão receber o Ativo na forma de um modelo BIM, que incorporará as respetivas necessidades futuras de cada área técnica, trará naturalmente mais-valias na gestão do mesmo no seu ciclo de vida. 
As mais-valias da aplicação da Metodologia BIM no Projeto de Execução do Sistema de Abastecimento de Água de Portel, ultrapassaram de forma significativa as vantagens da sua aplicabilidade para o Projetista, criando condições para que o Empreiteiro, a Fiscalização e a Entidade Gestora das Infraestruturas projetadas, usufruam dos benefícios da sua aplicação.

\section{Referências}

[1] António Aguiar Costa, Bruno de Carvalho Matos, Diogo Drumond; Inês Rodrigues, Guia de Contratação BIM - CT197-BIM; ONS/IST e apoio IPQ e IMPIC, 2017 